\title{
Akurasi Kriteria Voltase Elektrokardiografi Hipertrofi Ventrikel Kiri untuk Membedakan Jenis Geometri Hipertrofi Ventrikel Kiri
}

\author{
Octo Tumbur, Zainal Safri, Refli Hassan \\ Divisi Kardiologi, Departemen Ilmu Penyakit Dalam, \\ Fakultas Kedokteran, Universitas Sumatera Utara, Medan
}

\begin{abstract}
Abstrak
Perbedaan jenis geometri hipertrofi ventrikel kiri dikaitkan dengan risiko penyakit kardiovaskular yang berbeda. Ekokardiografi dengan bantuan kriteria voltase elektrokardiografi (EKG) hipertrofi ventrikel kiri dapat membedakan jenis geometri hipertrofi ventrikel kiri. Tujuan penelitian mengetahui peranan berbagai kriteria voltase EKG hipertrofi ventrikel kiri untuk membedakan jenis geometri hipertrofi ventrikel kiri. Dilakukan penelitian potong lintang periode Juni-November 2015 terhadap 100 pasien di poliklinik dan rawat inap kardiologi RSUP H. Adam Malik Medan. Dilakukan anamnesis, pengukuran indeks massa tubuh, serta pemeriksaan EKG dan ekokardiografi. Jika hasil kriteria EKG hipertrofi ventrikel kiri Sokolow-Lyon tidak dipenuhi maka didapatkan geometri ventrikel kiri normal dengan sensitivitas 60\%, spesifisitas 72,22\%, dan akurasi $71 \%$. Untuk jenis geometri eksentrik hipertrofi ventrikel kiri didapatkan bila Cornel voltase tidak dipenuhi, sensitivitasnya 25\%, spesifisitas 71,88\%, dan akurasi 55\%. Untuk jenis hipertrofi geometri konsentrik bila rasio RV6/V5 >1 dipenuhi, sensitivitasnya 55,56\%, spesifisitas 56,36\%, dan akurasi 56\%. Jika rasio RV6/V5 $>1$ tidak dipenuhi, jenis geometri konsentrik remodeling hipertrofi ditentukan dengan sensitivitas 55,56\%, spesifisitas 49,45\%, dan akurasi 50\%. Pada penelitian ini juga didapatkan sensitivitas dan spesifisitas kriteria Sokolow-Lyon untuk hipertrofi ventrikel kiri secara ekokardiografi dengan sensitivitas $72,22 \%$ dan spesifisitas $60,00 \%$, kriteria Cornel voltase untuk hipertrofi ventrikel kiri secara ekokardiografi dengan sensitivitas $77,78 \%$ dan spesifisitas 70,00\%, serta kriteria rasio RV6/V5 untuk hipertrofi ventrikel kiri secara ekokardiografi dengan sensitivitas 51,11\% dan spesifisitas 70,00\%. Secara keseluruhan, sensitivitas dan spesifisitas termasuk lemah. Simpulan, berbagai kriteria EKG ventrikel kiri dapat membedakan jenis geometri hipertrofi ventrikel kiri. Kriteria EKG hipertrofi kiri voltase, yaitu Sokolow-Lyon dan Cornel voltase sensitivitas dan spesifisitas lebih baik dibanding dengan rasio RV6/V5.
\end{abstract}

Kata kunci: Ekokardiografi, elektrokardiografi, geometri, hipertrofi, ventrikel

\section{Accuracy of Criteria Voltage Electrocardiography Left Ventricular Hypertrophy to Distinguish Types of Left Ventricular Hypertrophy Geometry}

\begin{abstract}
The different types of left ventricular hypertrophy geometry is associated with different risk of cardiovascular disease. Echocardiography is the gold standard for diagnosis of left ventricular hypertrophy. Electrocardiographic (ECG)left ventricular hypertrophy voltage criteria can distinguish the type of geometry of left ventricular hypertrophy. The purpose of this study to find out the role of various voltage ECG criteria to distinguish the type of geometry of left ventricle hypertrophy. A cross-sectional study was held from June to November 2015 on 100 patients in cardiology clinic and inpatient at Adam Malik Hospital, Medan, through anamnesis, body mass index measurement, ECG and echocardiography examinations. If the Sokolow-Lyon ECG criteria for left ventricular hypertrophy did not met, normal left ventricular geometry was diagnosed with 60\% sensitivity, $72.22 \%$ specificity and $71 \%$ accuracy. The eccentric left ventricular hypertrophy geometry was diagnosed if Cornel voltage was not fulfilled, with $25 \%$ sensitivity, 71.88\% specificity and 55\% accuracy. The concentric hypertrophy geometry was diagnosed if the RV6/ $\mathrm{V}_{5}$ ratio $>1$, with $55.56 \%$ sensitivity, $56.36 \%$ specificity and $56 \%$ accuracy. If the RV6/V5 ratio $>1$ are not met, concentric hypertrophic remodeling geometry was diagnosed with a sensitivity of $55.56 \%$, a specificity of $49.45 \%$ and an accuracy of 50\%. This study also found the sensitivity and specificity for left ventricular hypertrophy in echocardiography of Sokolow-Lyon criteria were $72.22 \%$ and $60.00 \%$, the Cornel voltage criteria with a sensitivity of $77.78 \%$ and a specificity of $70.00 \%$, and RV6/V5 ratio criteria with a sensitivity of $51.11 \%$ and a specificity of $70.00 \%$. The overall sensitivity and specificity was low. In conclusion, various criteria of ECG left ventricular geometry voltage can differentiate left ventricular hypertrophy geometry types. Sokolow-Lyon and Cornell voltage criteria are more sensitive and specific than the RV6/V5 ratio.
\end{abstract}

Key words: Echocardiography, electrocardiography, geometry, hypertrophy, ventricle

Korespondensi: Octo Tumbur. Divisi Kardiologi. Departemen Ilmu Penyakit Dalam, RSUP H. Adam Malik-Fakultas Kedokteran Universitas Sumatera Utara. Jln. Dr. Mansyur No. 5, Medan, Sumatera Utara, Indonesia. Telepon: +6261 8211045. HP: +6281376199101. E-mail: octotumbur@gmail.com 


\section{Pendahuluan}

Hipertrofi ventrikel kiri merupakan salah satu faktor risiko yang penting untuk angina pektoris, infark miokardium, gagal jantung, penyakit serebrovaskular, dan kematian yang mendadak. Hipertrofi ventrikel kiri memperburuk sirkulasi koroner sehingga akan menurunkan cadangan koroner dan mengakibatkan gangguan perfusi miokardium. ${ }^{1-3}$ Hipertrofi ventrikel kiri tersebut adalah peningkatan abnormal massa ventrikel kiri yang disebabkan oleh peningkatan beban kerja jantung kronik. Penyebabnya yang paling sering adalah pompa jantung yang meningkat terhadap peningkatan afterload seperti penyakit hipertensi dan stenosis aorta. ${ }^{2,4}$ Hipertrofi ventrikel kiri ini dapat ditentukan dengan pemeriksaan fisis, elektrokardiografik, radiologis (foto toraks, CTscan, MRI-CT, dll.), dan ekokardiografi. Secara ekokardiografi prevalensi hipertrofi ventrikel kiri pada penderita hipertensi lebih dari 50\%, sedangkan secara elektrokardiografi atau EKG didapatkan $15-20 \%{ }^{3.5-7}$

Ekokardiografi merupakan baku emas (gold standard) diagnosis hipertrofi ventrikel kiri karena lebih akurat dibandingkan dengan EKG. ${ }^{1}$ Berdasar atas studi oleh Gerdts dkk. ${ }^{3}$ diketahui ekokardiografi mampu membedakan geometri hipertrofi ventrikel kiri tersebut, yaitu concentric remodeling, eccentric $\mathrm{LV}$, atau concentric $\mathrm{LV}$. Jenis geometri hipertrofi itu dikaitkan dengan berbagai macam risiko penyakit kardiovaskular, misalnya concentric remodeling dengan risiko strok dan mortalitas kardiovaskular, eccentric LV dengan risiko infark jantung dan mortalitas kardiovaskular, serta concentric LV dengan hanya infark jantung. ${ }^{8-10}$

Karena ketersediaan ekokardiografi di daerah masih terbatas maka diperlukan penelitian untuk meningkatkan daya guna EKG. Elektrokardiografi merupakan metode diagnostik yang murah dan mudah untuk menegakkan diagnosis hipertrofi ventrikel kiri dengan spesifisitas tinggi, namun sensitivitasnya rendah. ${ }^{3.5,6}$

\section{Metode}

Penelitian observasional yang bersifat analitik dilaksanakan dengan cara potong lintang (cross sectional). Penelitian dilakukan di RSUP H. Adam Malik periode Juni-November 2015 mendapat persetujuan dari Komisi Etik Penelitian Bidang Kesehatan, Fakultas Kedokteran, Universitas Sumatera Utara/RSUP H. Adam Malik Medan dengan No. 772/KOMET/FKUSU/2015 terhadap subjek yang telah menandatangani persetujuan ikut dalam penelitian (informed consent).

Penelitian menggunakan rumus besar sampel uji diagnostik dengan minimal sampel 99 (nilai $\mathrm{Za}=1,96$; nilai sensitivitas $=20 \%$; nilai $\mathrm{d}=10 \%$; nilai prevalensi $62 \%$ ); pria dan wanita berusia $>40$ tahun. Kriteria inklusi adalah pasien diduga berpenyakit jantung hipertrofi ventrikel kiri. Kriteria eksklusi adalah tidak diperiksa EKG dan ekokardiografi lengkap, pasien menderita edema generalisata, keganasan, dan yang menggunakan imunosupresan.

Kriteria EKG untuk menentukan hipertrofi ventrikel kiri pada penelitian ini adalah kriteria voltase: kriteria Sokolow-Lyon $\left(\mathrm{SV}_{1}+\mathrm{RV} 5\right.$ cutoff $>35 \mathrm{mmV})$, Cornell voltase $\left(\mathrm{SV}_{3}+\mathrm{RaVL}=\right.$ cut off wanita $>22 \mathrm{mmV}$, laki-laki $>28 \mathrm{mmV}$ ), dan rasio RV6/V5 (cut-off $>1$ ). Pada penelitian ini ekokardiografi digunakan untuk mendapatkan hasil pengukuran LVEDD, IVSd, dan juga PWd. Kemudian dari hasil pengukuran tersebut dengan mempergunakan bantuan dari kalkulator situs internet LV mass (MDMath | Canadian Society of Echocardiography), didapatkan 4 jenis geometri hipertrofi ventrikel kiri, yaitu geometri normal, hipertrofi ventrikel kiri eksentrik, hipertrofi ventrikel kiri konsentrik, dan hipertrofi ventrikel kiri konsentrik remodeling.

Analisis statistik menggunakan program SPSS v.20 dengan uji Kolmogorov-Smirnov untuk menilai normalitas distribusi data. Uji diagnostik tabel $2 \times 2$ menilai sensitivitas dan spesifisitas kriteria EKG hipertrofi ventrikel kiri untuk jenis geometri berdasar atas hasil ekokardiografi. Uji kurva receiving operating characteristic (ROC) dilakukan untuk mendapatkan nilai area under curve (AUC). Penentuan akurasi kriteria voltase EKG hipertrofi ventrikel kiri untuk membedakan jenis geometri hipertrofi ventrikel kiri berdasar atas penelitian oleh Tomita dkk. ${ }^{11}$ Hasil $\mathrm{p}<0,05$ dianggap signifikan.

\section{Hasil}

Selama periode penelitian diperoleh 100 subjek penelitian dengan karakteristik usia median 56,5 tahun (min. 41 tahun-maks. 85 tahun), 47 lakilaki (47\%), dan 53 perempuan (53\%), serta IMT rata-rata $21,99 \mathrm{~kg} / \mathrm{m}^{2}$ (Tabel 1 ).

Dari hasil EKG didapatkan tinggi median kriteria Sokolow-Lyon: 35 (min. 6-maks. 41) $\mathrm{mmV}$, tinggi median kriteria Cornel voltase: 24 (min. 8-maks. 30) mmV, dan nilai median rasio 
Tabel 1 Karakteristik Dasar Subjek Penelitian

\begin{tabular}{|c|c|c|}
\hline Variabel & n=100 pasien & $\mathbf{p}^{*}$ \\
\hline Usia (tahun) & $56,5(41-85)$ & 0,004 \\
\hline $\begin{array}{l}\text { Jenis kelamin } \\
\text { Laki-laki } \\
\text { Perempuan }\end{array}$ & $\begin{array}{l}47(47 \%) \\
53(53 \%)\end{array}$ & \\
\hline Berat badan (kg) & $57,91 \pm 7,53$ & 0,106 \\
\hline Tinggi badan $(\mathrm{cm})$ & $162(151-173)$ & 0,004 \\
\hline $\operatorname{IMT}^{\mathrm{a}}\left(\mathrm{kg} / \mathrm{m}^{2}\right)$ & $21,99 \pm 1,95$ & 0,137 \\
\hline Kriteria Sokolow-Lyon ${ }^{\mathrm{b}}(\mathrm{mmV})$ & $35(6-41)$ & $\mathbf{0 , 0 0}$ \\
\hline Kriteria Cornel voltase $^{\mathrm{c}}(\mathrm{mmV})$ & $24(8-30)$ & $\mathbf{0 , 0 0}$ \\
\hline Kriteria rasio $\mathrm{RV} 6 / \mathrm{V}^{\mathrm{d}}$ & $0,9(0,4-4)$ & $\mathbf{0 , 0 0}$ \\
\hline $\begin{array}{l}\text { Kriteria ekokardiografi } \\
\operatorname{LVEDD}^{\mathrm{e}}(\mathrm{mm}) \\
\operatorname{IVSD}^{\mathrm{f}}(\mathrm{mm}) \\
\operatorname{PWD}^{\mathrm{g}}(\mathrm{mm})\end{array}$ & $\begin{array}{c}50,79 \pm 9,83 \\
12,25(6,6-29,0) \\
11,0(5,2-20)\end{array}$ & $\begin{array}{c}0,200 \\
0,10 \\
\mathbf{0 , 0 0 3}\end{array}$ \\
\hline $\begin{array}{l}\text { Hasil ekokardiografi } \\
\text { LV mass }{ }^{\mathrm{h}}(\mathrm{g}) \\
\mathrm{LVMI}^{\mathrm{i}}\left(\mathrm{g} / \mathrm{m}^{2}\right) \\
\text { RWT }^{\mathrm{j}}\end{array}$ & $\begin{array}{c}221(99-774) \\
134,5(57-492) \\
0,45(0,2-1,26)\end{array}$ & $\begin{array}{l}\mathbf{0 , 0 0 3} \\
\mathbf{0 , 0 0 2} \\
\mathbf{0 , 0 0 9}\end{array}$ \\
\hline $\begin{array}{l}\text { Jenis geometri } \\
\text { Normal geometri (\%) } \\
\text { Concentric remodeling LVH (\%) } \\
\text { Concentric hypertrophy LVH (\%) } \\
\text { Eccentric hypertrophy LVH (\%) }\end{array}$ & $\begin{array}{c}10(10 \%) \\
9(9 \%) \\
45(45 \%) \\
36(36 \%)\end{array}$ & \\
\hline
\end{tabular}

Keterangan: *tes Kolmogorov-Smirnov; aindeks massa tubuh; ${ }^{\mathrm{b}}$ cut-off $>38 \mathrm{mmV}$; ${ }^{\mathrm{c}}$ cut-off: laki-laki $>28 \mathrm{mmV}$, perempuan $>22 \mathrm{mmV}$; ${ }^{\mathrm{d}} \mathrm{R}$ cut-off $>0,7$; ${ }^{\mathrm{e}}$ left ventricular end-diastolic dimension; ${ }^{\mathrm{f}}$ interventricular septal

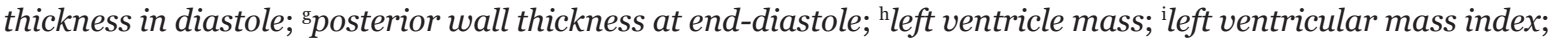
'relative wall thickness

RV6/V5 0,9 (min. 0,4-maks. 4).

Hasil ekokardiografi berupa LVEDD nilai rata-rata 50,79 $\pm 9,83 \mathrm{~mm}$, IVSD nilai median 12,25 (min. 6,6-maks. 29,0) mm, dan PWD nilai median 11 (min. 5,2-maks. 20) mm. Melalui perhitungan dari hasil ekokardiografi didapatkan hasil LV mass nilai median 221 (min. 99-maks. 774) g, LVMI nilai median 134,5 (min. 57-maks.

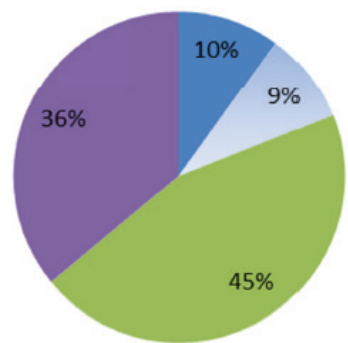

n Geometri normal

Geometri konsentrik remodeling

= Geometri hipertropi konsentrik

- Geometri hipertropi eksentrik

\section{Gambar 1 Persentase Jenis Geometri Ventrikel Kiri}

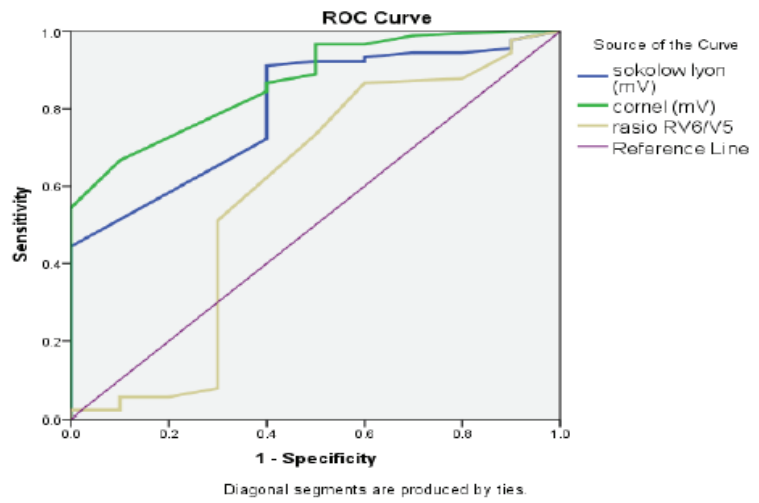

\section{Gambar 2 Kurva ROC untuk Sensitivitas dan Spesifisitas Kriteria EKG LVH}

Keterangan: kriteria EKG Sokolow Lyon: AUC $=79,9 \%(\mathrm{p}=0,002 ;$ IK95\% 67,3-92,6\%); kriteria EKG Cornel voltase: $\mathrm{AUC}=86,8 \%(\mathrm{p}=0,000 ; \mathrm{IK} 95 \%$ 77,3-96,4\%); kriteria rasio RV6/V5: $\mathrm{AUC}=58,3 \%(\mathrm{p}=0,389 ; \mathrm{IK} 95 \% 35-81,7 \%)$ 
Tabel 2 Sensitivitas dan Spesifisitas Kriteria EKG pada Hipertrofi Ventrikel Kiri

\begin{tabular}{llccccccc}
\hline Kriteria EKG & $\begin{array}{c}\text { Cut-off value } \\
(\mathbf{m V})\end{array}$ & $\begin{array}{c}\text { Sensiti- } \\
\text { vitas (\%) }\end{array}$ & $\begin{array}{c}\text { Spesifi- } \\
\text { Sitas } \\
\mathbf{( \% )}\end{array}$ & $\mathbf{R K P}^{*}$ & $\mathbf{R K N}^{+}$ & $\begin{array}{c}\mathbf{N D P}^{\boldsymbol{\theta}} \\
\mathbf{( \% )}\end{array}$ & $\begin{array}{c}\mathbf{N D N}^{\boldsymbol{a}} \\
\mathbf{( \% )}\end{array}$ & $\begin{array}{c}\text { Akurasi } \\
\text { (\%) }\end{array}$ \\
\hline Sokolow-Lyon & $\geq 3,5$ & 72,22 & 60,00 & 1,81 & 0,46 & 94,2 & 19,35 & 71 \\
Cornell voltase & $\begin{array}{l}\text { Laki-laki }>2,8 \\
\text { Perempuan }>2,2\end{array}$ & 77,78 & 70,00 & 2,59 & 0,32 & 95,89 & 25,93 & 77 \\
Rasio RV6/V5 & $>1$ & 51,11 & 70,00 & 1,7 & 0,7 & 93,88 & 13,73 & 58,3 \\
\hline
\end{tabular}

Keterangan: * rasio kemungkinan positif, ${ }^{+}$rasio kemungkinan negatif, ${ }^{\theta}$ nilai duga positif, ${ }^{a}$ nilai duga negatif

492) $\mathrm{g} / \mathrm{m}^{2}$. Hasil normal geometri $10 \%$, concentric remodeling $\mathrm{LVH} 9 \%$, concentric hypertrophy LVH 45\%, dan eccentric hypertrophy LVH 36\% (Gambar 1).

Dilakukan uji diagnostik menilai sensitivitas dan spesifisitas kriteria EKG pada hipertrofi ventrikel kiri dipakai ekokardiografi. Didapatkan sensitivitas dan spesifisitas kriteria SokolowLyon sebesar $72,22 \%$ dan $60,00 \%$, sedangkan menurut kriteria Cornel voltase sebesar $77,78 \%$ dan $70,00 \%$. Sensitivitas dan spesifisitas rasio RV6/V5: 51,11\% dan 70,00\% (Tabel 2). Dengan uji ROC didapatkan kurva sesuai Gambar 2.

Uji sensitivitas dan spesifisitas penentuan jenis hipertrofi ventrikel kiri pada 'flow chart' seperti pada penelitian Tomita dkk. ${ }^{11}$ (Gambar 3).

\section{Pembahasan}

Penelitian menghasilkan 'flow chart' (diagram) untuk membedakan jenis geometri hipertrofi ventrikel kiri dengan memakai kriteria EKG hipertrofi ventrikel kiri voltase (Gambar 3). Diagram merujuk pada penelitian yang dilakukan oleh Tomita dkk. ${ }^{11}$ Walaupun hasil sensitivitas dan spesifisitas termasuk lemah, flow chart tersebut membedakan jenis geometri hipertrofi ventrikel kiri secara praktis menggunakan kriteria EKG. Kriteria EKG hipertrofi ventrikel kiri SokolowLyon tidak dipenuhi maka didapatkan geometri ventrikel kiri normal dengan sensitivitas $60 \%$, spesifisitas $72,22 \%$, dan akurasi $71 \%$, sedangkan pada jenis geometri eksentrik hipertrofi ventrikel kiri didapatkan jika Cornel voltase tidak dipenuhi dengan sensitivitas $25 \%$, spesifisitas $71,88 \%$, dan akurasi 55\%. Pada jenis geometri konsentrik hipertrofi ditentukan apabila rasio $\mathrm{RV} 6 / \mathrm{V}_{5}>1$ dipenuhi dengan sensitivitas 55,56\%, spesifisitas $56,36 \%$, dan akurasi $56 \%$. Bila rasio RV6/V5 >1 tidak dipenuhi maka didapatkan jenis geometri konsentrik remodeling hipertrofi: sensitivitas $55,56 \%$, spesifisitas $49,45 \%$, dan akurasi $50 \%$. Hasil uji sensitivitas dan spesitivitas dinyatakan rendah karena nilai kurang dari 90\%, tetapi

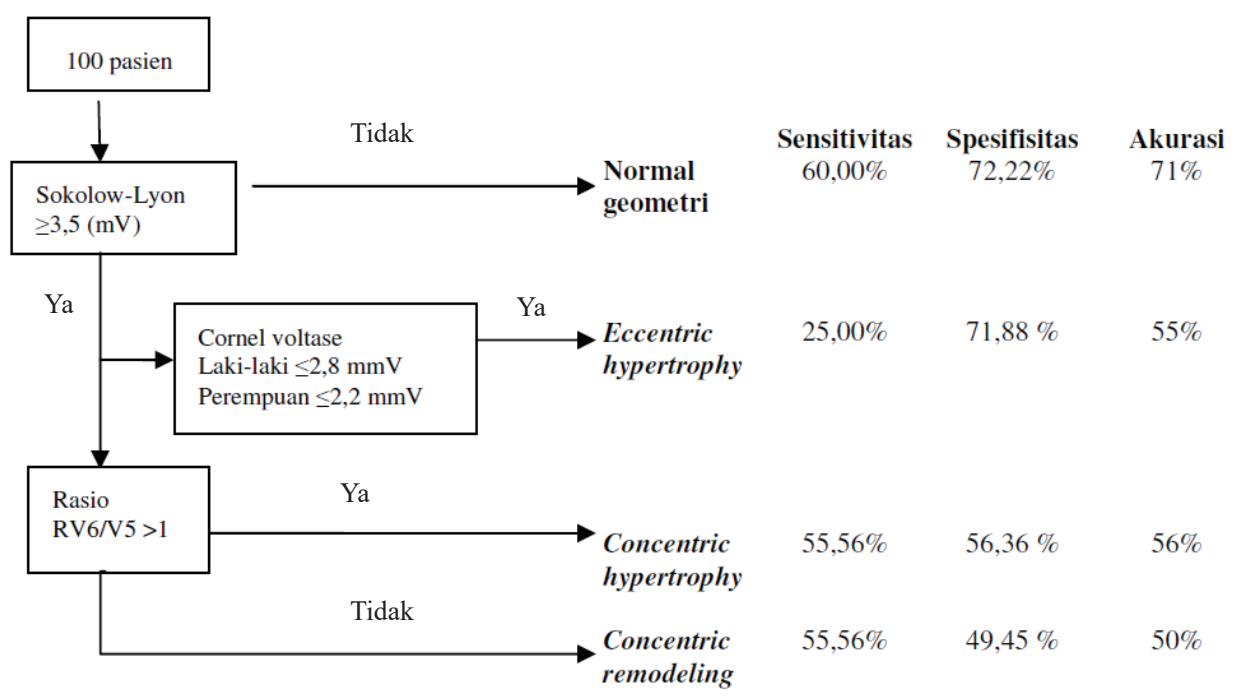

Gambar 3 'Flow Chart' Identifikasi Gambaran Geometri Hipertrofi Ventrikel Kiri 
tidak berarti flow chart tersebut tidak dapat diaplikasikan oleh karena diperoleh nilai uji diagnostik yang telah dilaksanakan. Diperlukan pemahaman cara penggunaan flow chart tersebut tetap kembali kepada pengukuran gold standard penentuan jenis geometri hipertrofi ventrikel kiri menggunakan ekokardiografi.

Diagram pada Gambar 3 memiliki kelemahan, yaitu suspek bias pemilihan pasien karena tidak diketahui penyebab penyakitjantungnya sehingga pasien dengan besar jantung normal dapat masuk dalam penelitian. Sebelum menggunakan diagram yang akan diaplikasikan dalam klinis, diperlukan kemampuan para klinisi untuk interpretasi klinis pasien berdasar anamnesis, pemeriksaan fisis, dan imaging untuk memastikan penyakit kronik yang telah diketahui terkait dengan hipertrofi ventrikel kiri, misalnya hipertensi kronik. Kita dapat mengetahui implikasi hipertensi kronik terhadap pasien kita, yaitu apakah sudah terjadi jenis hipertrofi ventrikel kiri yang normal atau abnormal, serta prognosis pada jenis hipertrofi ventrikel kiri yang abnormal. Dengan demikian, dapat dilaksanakan upaya meningkatkan terapi atau penatalaksanaan, pemeriksaan penunjang lebih lanjut untuk faktor-faktor risiko terkait, dan upaya rujukan untuk tata laksana bila tidak tersedia fasilitas di tempat kita.

Pada penelitian ini juga didapatkan sensitivitas dan spesifisitas EKG untuk hipertrofi ventrikel kiri: kriteria Sokolow-Lyon dengan sensitivitas $72,22 \%$ dan spesifisitas $60,00 \%$ untuk hipertrofi ventrikel kiri secara ekokardiografi, kriteria Cornel voltase dengan sensitivitas $77,78 \%$ dan spesifisitas 70,00\% untuk hipertrofi ventrikel kiri secara ekokardiografi, serta kriteria rasio RV6/ $\mathrm{V}_{5}$ dengan sensitivitas $51,11 \%$ dan spesifisitas 70,00\% untuk hipertrofi ventrikel kiri secara ekokardiografi (Tabel 2). Secara keseluruhannya sensitivitas dan spesifisitas termasuk lemah, tetapi kriteria Sokolow-Lyon dan Cornel voltase lebih baik dibanding dengan rasio RV6/V5. Hal ini menunjukkan kriteria Sokolow-Lyon dan Cornel voltase lebih baik dalam menentukan jenis geometri hipertrofi ventrikel kiri normal atau abnormal sehari-hari.

Sohaib dkk.12 sudah menggunakan magnetic resonance imaging atau MRI kardiovaskular untuk dapat mengetahui hipertrofi ventrikel kiri dihasilkan sensitivitas 50\% dan spesifisitas $71,1 \%$ untuk kriteria Sokolow-Lyon, sedangkan untuk kriteria Cornel voltase sensitivitas 25\% dan spesifisitas 88,7\%. Pada penelitian Ahn dkk. ${ }^{13}$ ditemukan kriteria EKG untuk hipertrofi ventrikel kiri kriteria Sokolow-Lyon: sensitivitas $3,3 \%$ dan spesifisitas 95,6\% serta Cornel voltase: sensitivitas 6,6\% dan spesifisitas 96\%. Ogunlade dan Akintomide ${ }^{14}$ menyimpulkan kriteria EKG untuk hipertrofi ventrikel kiri dengan kriteria Sokolow-Lyon: sensitivitas 58,62\% dan 60,66\% serta Cornel voltase: sensitivitas $51,72 \%$ dan spesifisitas $66,67 \%$.

Kriteria rasio RV6/V5 jarang dipergunakan karena sensitivitas dan spesifisitasnya rendah. Romhilt dkk. ${ }^{16}$ mendapatkan sensitivitas 22,5\% dan spesifisitas $89,5 \%$. Penelitian Tomita dkk. ${ }^{11}$ didapatkan sensitivitas 59\% dan spesifisitas 30\% (khusus rasio RV6/V5 >0,7) serta penelitian oleh Hanna dkk. ${ }^{18}$ mendapatkan sensitivitas $79 \%$ dan spesifisitas $28 \%$. Berdasar atas kurva ROC (Gambar 2) pada penelitian ini kriteria SokolowLyon dan Cornel voltase lebih baik daripada rasio R V6/V5. Jika dibandingkan antara kriteria Sokolow-Lyon dan Cornel voltase ditemukan Cornel voltase $\mathrm{AUC}=86,8 \%$ ( $\mathrm{p}=0,000$; IK95\% 77,3-96,4\%) lebih baik daripada Sokolow-Lyon AUC $=79,9 \%$ ( $p=0,002 ;$ IK95\% 67,3-92,6\%). Pada penelitian ini kriteria rasio RV6/V5 membantu membedakan jenis geometri hipertrofi ventrikel kiri concentric hypertrophy dengan concentric remodeling.

Pada systematic review oleh Pewsner dkk. ${ }^{15}$ terhadap 21 penelitian mengenai akurasi kriteria EKG pada hipertrofi ventrikel kiri ditemukan berbagai nilai sensitivitas dan juga spesifisitas. Disimpulkan bahwa akurasi penggunaan kriteria EKG untuk deteksi LVH kurang memuaskan dan implikasi klinis yang diharapkan adalah bahwa penggunaan kriteria EKG penting untuk rujukan segera pemeriksaan lebih lanjut seperti ekokardiografi dan laboratorium untuk faktor risiko kardiovaskular.

Bacharova dkk. ${ }^{17}$ berpendapat masih ada peran EKG dalam penatalaksanaan hipertrofi ventrikel kiri, pertama karena ketersediaan yang luas dan biaya yang rendah; indikator EKG masih berperan dalam menilai perkembangan atau gagalnya terapi; dan mempunyai peranan prognostik untuk deteksi faktor risiko kardiovaskular.

\section{Simpulan}

Pada penelitian ini berbagai kriteria voltase EKG ventrikel kiri untuk membedakan jenis geometri hipertrofi ventrikel kiri mempunyai sensitivitas dan spesifisitas lemah. Akurasi kriteria SokolowLyon dan Cornel voltase lebih baik dibanding dengan kriteria rasio $\mathrm{RV} 6 / \mathrm{V}_{5}$, tetapi sensitivitas 
dan spesifisitas juga termasuk lemah.

\section{Daftar Pustaka}

1. Devereux R, Roman M. Left ventricular hypertrophy in hypertensive: stimuli, patterns, and consequences. Hypertens Res. 1999;22(1):1-9.

2. East MA, Jollis JG, Nelson CL, Marks D, Peterson ED. The influence of left ventricle hypertrophy on survival in patients with coronary artery disease: do race and gender matter? J Am Coll Cardiol. 2003;41(6):94954 .

3. Gerdts E, Cramariuc D, de Simone G, Wachtell K, Dahlöf B, Devereux RB. Impact of left ventricular geometry on prognosis in hypertensive patients with left ventricular hypertrophy (the LIFE study). Eur J Echocardiogr. 2008;9(6):809-15.

4. Bauml MA, Underwood DA. Left ventricular hypertrophy: an overlooked cardiovascular risk factor. Cleve Clin J Med. 2010;77(6):3817.

5. Efendi D. Korelasi dispersi QT dengan hipertrofi ventrikel kiri pada penderita hipertensi. Bagian Ilmu Penyakit Dalam, Fakultas Kedokteran, Universitas Sumatera Utara, 2003 [diunduh 19 Februari 2015]. Tersedia dari: http:/library.usu.ac.id/ download/fk/penydalam-dasrilefendi_pdf.

6. Panggabean MM. Penyakit jantung hipertensi. Dalam: Sudoyo AW, Setiyohadi B, Alwi I, Simadibrata M, Setiati S, penyunting. Buku ajar ilmu penyakit dalam. Edisi ke5. Jakarta: Interna Publishing; 2009. hlm. $1265-7$.

7. Kotchen TA. Hypertensive vascular disease. Dalam: Loscalzo J, penyunting. Harrison's cardiovascular medicine. New York: McGrawHill Companies, Inc.; 2010. hlm. 429-35.

8. Mirtha DV, Angel MF, Nilvia AB, Mayte DF, Enrique DF, Arturo MC. Prevalence of left ventricular hypertrophy in patients with essential high blood pressure. 2nd Virtual Congress of Cardiology, Argentine Federation of Cardiology, 1999-2001 [diunduh 19 Februari 2015]. Tersedia dari: http://www. fac.org.ar/tcve/llave/tl101i/tl101.PDF.

9. Houser SR, Margulies KB, Murphy AM, Spinale FG, Francis GS, Prabhu SD, dkk.; American Heart Association Council on Basic Cardiovascular Sciences, Council on Clinical Cardiology, and Council on Functional
Genomics and Translational Biology. Animal models of heart failure: a scientific statement from the American Heart Association. Circ Res. 2012;111(1):131-50.

10. Gaasch WH, Zile MR. Left ventricular structural remodeling in health and disease: with special emphasis on volume, mass, and geometry. J Am Coll Cardiol. 2011;58(17):1733-40.

11. Tomita S, Ueno H, Takata M, Yasumoto K, Tomoda, Inoue H. Relationship between electrocardiographic voltage and geometric patterns of left ventricular hypertrophy in patients with essential hypertension. Hypertens Res. 1998;21(4):259-66.

12. Sohaib SM, Payne JR, Shukla R, World M, Pennell DJ, Montgomery HE. Electrocardiographic (ECG) criteria for determining left ventricular mass in young healthy men; data from the LARGE Heart study. J Cardiovasc Magn Reson. 2009;11:2.

13. Ahn MS, Yoo BS, Lee JH, Lee JW, Youn YJ, Ahn SG, dkk. Addition of N-terminal pro-B-type natriuretic peptide levels to electrocardiography criteria for detection of left ventricular hypertrophy: the ARIRANG study. J Korean Med Sci. 2015;30(4):407-13.

14. Ogunlade O, Akintomide AO. Assessment of voltage criteria for left ventricular hypertrophy in adult hypertensives in southwestern Nigeria. J Cardiovasc Dis Res. 2013;4(1):44-6.

15. Pewsner D, Jüni $P$, Egger M, Battaglia $M$, Sundström J, Bachmann LM. Accuracy of electrocardiography in diagnosis of left ventricular hypertrophy in arterial hypertension: systematic review. BMJ. 2007;335(7622):711.

16. Romhilt DW, Bove KE, Norris RJ, Conyers E, Conradi S, Rowlands DT, dkk. A critical appraisal of the electrocardiographic criteria for the diagnosis of left ventricular hypertrophy. Circulation. 1969;40(2):18595.

17. Bacharova L, Schocken D, Estes EH, Strauss D. The role of ECG in the diagnosis of left ventricular hypertrophy. Curr Cardiol Rev. 2014;10(3):257-61.

18. Hanna EB, Glancy DL, Oral E. Sensitivity dan specificity of frequently used electrocardiographic criteria for left ventricular hypertrophy in patients with anterior wall myocardial infarction. Proc Bayl Univ Med Cent. 2010;23(1):15-8. 